\title{
A Malfunction Example of DC Power Supply of the Power Source System in a Certain Type of Equipment
}

\author{
Xiaofang LOU, Huihua CHENG, Chuanfei QIU, Quanzhi ZHOU \\ Wuhan Mechanical Technology College, Wuhan, China
}

\begin{abstract}
A certain type of equipment including DC and AC two power supply ways, DC power supply is vital when there is no AC power. In this paper, a malfunction which is encountered in the process of DC power supply for such type of equipment is analyzed and excluded, from the analysis of such malfunction, we can see the relay is used more in the process of DC power supply, is an important component, and is easily to break down, is the key point for us to exclude the malfunction.
\end{abstract}

KEYWORD: Power Source System; DC Power Supply; Malfunction; Relay

\section{MALFUNCTION PHENOMENON}

In a combat training, a malfunction happened when a military hardware of particular model was supplied by DC power of the power source system. If the switch of DC power supply was pressed, a sound as "Di" was emitted and continues to exist. At this time, the voltmeter for power supply displayed a voltage close to $0 \mathrm{~V}$, which indicates the equipment was unserviceable. About 10 seconds later, a loud sound of "Di" was emitted, and the voltage recovered to more or less $24 \mathrm{~V}$, and then the equipment returned to normal state.

\section{MALFUNCTION DIAGNOSIS}

The schematic diagram of power system in this type of equipment is illustrated as figure 1 .

Fig.1 shows complexity of the electronic circuit, but as the issue is only involved in the supplying part of DC power system, so we only consider the electronic circuit of DC power portion. Most parts of the electronic circuit in figure 1 belongs to the $\mathrm{AC}$ power, the electronic circuit for DC power locates in the left and bottom part of the Fig. 1, as is illustrated by Fig. 2.

In Fig. 2, switch S3 of DC power system is in the "off" status and it keeps closed. Press the switch to make it closed when DC supplement is necessary. Switch S4 of DC power system is in the "on" status and it remains off in the normal case. Press the switch when power cut is needed. X2 is input outlet of DC power, whose working process is summarized in detail.

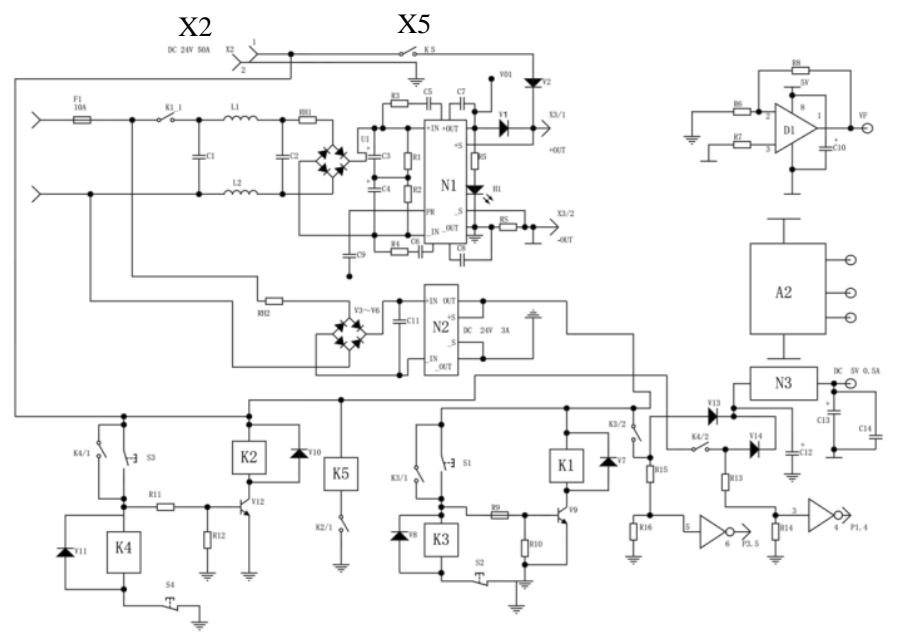

Fig.1 schematic diagram for the circuit board of power supply system

The process of DC power supply of the particular equipment is as follows:

(1) pin 1 and pin 2 of X2 (input of $24 \mathrm{~V}$ DC voltage) $\rightarrow 1$ pin of $\mathrm{X} 2 \rightarrow$ control circuit of DC power supply.

(2) when the DC power supply works, pressed the DC "on" switch S3: S3 is on (pressed moment) $\rightarrow$ $\mathrm{K} 4$ works (S4 is a normally closed switch) $\rightarrow \mathrm{K} 4 / 1$, $\mathrm{K} 4$ / 2 on $\rightarrow$ when S3 is off, it is replaced by K4 / 1 for conduction of the circuit. $\rightarrow 24 \mathrm{~V}$ voltage passes $\mathrm{K} 4$ / 1, and is partial pressured by R11 and R12 so that V12 is conducted $\rightarrow$ after current flowing throughK2, K2 is conducted $\rightarrow \mathrm{K} 2 / 1$ on $\rightarrow \mathrm{K} 5$ works $\rightarrow$ switch K5 on 
(3) $24 \mathrm{~V} \mathrm{DC}$ voltage $\rightarrow$ pin 1 and pin 2 of X2 $\rightarrow$ switch K5 $\rightarrow \mathrm{V} 2 \rightarrow \mathrm{X} 3 / 1 \rightarrow$ providing $24 \mathrm{~V} \mathrm{DC}$ voltage to supply electrical equipments with needs of DC power.

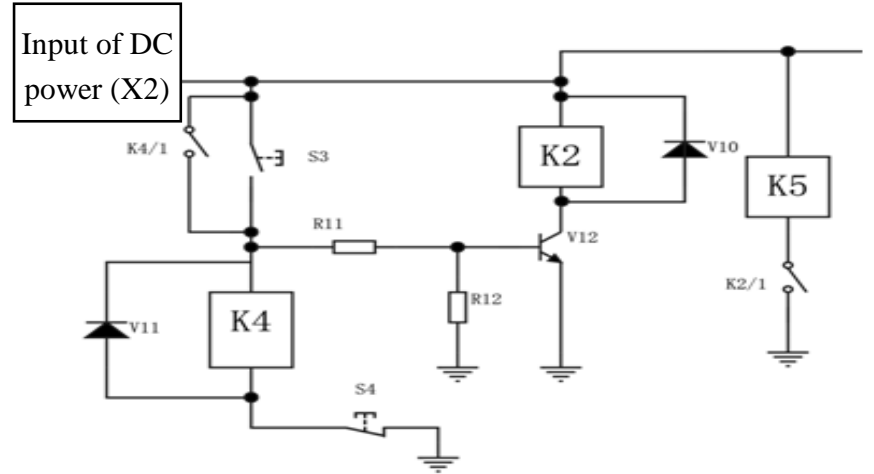

Fig. 2 control circuit of DC power supply system

The working process of DC power supply is relatively simple from analysis of the electronic circuit, but the above malfunction symptom is a kind of rare problem and never happens before. The malfunction is possibly caused by power input, or electronic circuit, or switches, or electric relay, or triodes that control the electric relay. The actual cause for such a fault will be illustrated in the troubleshooting part.

\section{TROUBLESHOOTING}

In order to solve the malfunction, it is needed to locate the malfunction point by checking step-bystep according to the process of system power supply.

\subsection{Power input problem}

First check whether the power input exists or not, and then test the DC input outlet of X2. When turn on the DC switch, if there is $24 \mathrm{~V}$ arising, then the input of the power supply is normal.

\subsection{Wire problem}

In the case of power on, test the connection between wires of the various components. First check whether there is anything broken inside with the naked eye, and then use a multimeter to test the resistance profile connectivity among components under the guidance of the connection on the circuit diagram above. Wire connection of the entire power supply turns out to be unproblematic. According to the connection on the circuit diagram, the various components are connected correctly, so the problem does not lie in wires of the power supply.[1]

\subsection{Switch problem}

There are two switches mainly used in the whole process of DC power supply, S3 and S4, one of which is a normally open switch, and another a normally closed switch. It is necessary to test whether these two switches are normal or not.

First test the voltage of switch S3.Turn the multimeter to the gear position of DC voltage profile, then the red-end probe touches the switch, and the black-end probe is pointed to the ground. Do not use the two probes directly connect the two ends of switch, because it is meaningless due to the certain voltage of $0 \mathrm{~V}$. S3 is a normally open switch, in a usual case, one end is $24 \mathrm{~V}$, and one end is $0 \mathrm{~V}$. When the switch is pressed and the voltage across the switch is tested, there ought to be some change. If the voltage across the switch is $0 \mathrm{~V}$, it means that the switch is normal.

The next step is to test switch S4, and the test method is similar to that of the S3. S4 is a normally closed switch, it ought to be 0 Vin a usual case. When the switch is pressed and the voltage across the switch is tested, if the voltage across the switch of one end is $24 \mathrm{~V}$ and another end is $0 \mathrm{~V}$, it means that the switch $\mathrm{S} 4$ is normal as well.

\subsection{Problems of relays and triodes in relay controllers}

According to the above symptoms and analysis, the final suspect comes to be degraded performance of some triodes in relays and relay controllers. Using an alternative to test the fault is a possible solution. Because of complexity of the relay wiring and difficult welding, it is not easy to be replaced. Before replacement of the relays, triodes of the control relay are replaced with the substitution firstly. However, after the replacement of the triode V12, DC power supply is found to recover normal finally, then troubleshooting is accomplished, and it indicates it is the degraded performance of the triode V12 that leads to such malfunction of the DC power supply.

\section{REFERENCES}

[1] Wei Zhang \& Chuanfei Qiu \& Junxian Liu \& Quanzhi Zhou \& Zhichao SHao. 2010. Design and Implementation of DBF Testing System Based on FPGA. FCCC 2010:202205. 